\title{
Brachydactyly type B2
}

INSERM

\section{Source}

INSERM. (1999). Orphanet: an online rare disease and orphan drug data base.

Brachydactyly type B2. ORPHA:140908

Brachydactyly type B2 is a rare, genetic congenital limb malformation disorder characterized by hypoplasia/aplasia of distal and/or middle phalanges in fingers and toes II-V (frequently severe in fingers/toes IV-V, milder in fingers/toes II-III) in association with proximal, and occasionally distal, symphalang ism, fusion of carpal/tarsal bones and partial cutaneous syndactyly. Additional reported features include proximal placement of thumbs, sensorineural hearing loss and farsightedness. 